\title{
Evaluation of the Transport Parameters and Physiochemical Properties of Forward Osmosis Membranes after Treatment of Produced Water
}

\author{
Bryan D. Coday ${ }^{1}$, Christiane Hoppe-Jones ${ }^{2}$, Daniel Wandera ${ }^{3}$, Jayraj Shethji ${ }^{3}$, Jack Herron, Keith Lampi, \\ Shane A. Snyder ${ }^{2}$, and Tzahi Y. Cath ${ }^{1, *}$ \\ ${ }^{1}$ Colorado School of Mines, Golden, CO, USA \\ ${ }^{2}$ University of Arizona, Tucson, AZ, USA \\ ${ }^{3}$ Hydration Technology Innovations, Albany, OR, USA \\ * Corresponding author: \\ Address: 1500 Illinois St., Golden, CO 80401, USA \\ Telephone: +1-303-273-3402 \\ E-mail address: tcath@mines.edu \\ A manuscript prepared for possible publication the \\ Journal of Membrane Science
}

June 2015

(C) 2015. This manuscript version is made available under the Elsevier user license http://www.elsevier.com/open-access/userlicense/1.0/ 


\begin{abstract}
The application of semipermeable membranes for dewatering of complex oil and gas wastewaters continues to be a topic of increasing interest. Several studies have explored the fouling propensity and contaminant rejection of osmotically driven membranes during forward osmosis (FO) treatment of produced waters; however, none have investigated changes in membrane transport and physiochemical properties after exposure to these feed streams. In this study we discuss the impacts of produced water exposure on the transport and active layer surface properties of cellulose triacetate (CTA) and polyamide thin-film composite (TFC) FO membranes. While produced water exposure yields some, albeit minor changes to the membrane performance and surface characteristics of the CTA and the traditional TFC membranes, close to $50 \%$ reduction in reverse salt flux and contaminant transport was observed for a surface-modified TFC FO membrane; only minimal changes in water permeability were recorded. Results of this study demonstrate the chemical and physical robustness of FO membranes for treatment of oil and gas wastewaters, and they highlight a knowledge gap that exists in membrane polymer selection and contaminant interactions with the membrane polymer matrix that should be further addressed in future membrane fouling studies.
\end{abstract}

Keywords: forward osmosis; produced water; fracturing flowback wastewater; contaminant rejection; membrane fouling 


\section{Introduction}

\subsection{Separation of complex wastewaters by semipermeable polymeric membranes}

The application of semipermeable polymeric membranes for dewatering of complex feed streams, and especially those laden with a variety of organic compounds and hydrocarbons, has increased in recent years [1-8]. This is especially true in the oil and gas industry, where rapid oil field exploration has spurred the development of tight-barrier membrane processes for treatment of wastewaters like hydraulic fracturing flowback and produced waters [3-6, 8-15]. While exceedingly higher total dissolved solids (TDS) concentrations in produced water has been a traditional hurdle for a variety of water treatment technologies, the prevalence of dissolved organic and aromatic compounds in oil field wastewaters has gained significant attention [16-21]. The organic compounds present in feed streams like produced water exhibit a wide range of physiochemical properties and concentrations; however, their potential effects on membrane performance and sustainability is not yet clear. The effects of produced water and organic compound exposure on the properties of pressure driven membranes (e.g., water permeability, contaminant rejection, and membrane surface characteristics) has only been briefly investigated [7, 22]. Polyamide thin-film composite (TFC) membranes exhibited notable changes in membrane performance and physiochemical properties, while no significant changes were reported for a traditional cellulose triacetate (CTA) RO membrane. Several studies have explored the application of osmotically driven membranes (i.e., forward osmosis (FO)) for similar feed waters [13, 23-26]; however, none have specifically investigated the changes in membrane performance and active layer surface properties.

\subsection{Produced water treatment: Deviations in FO membrane performance}

The impacts of FO membrane selection and system operating conditions on fouling propensity and overall membrane performance were recently investigated during our produced water treatment study [9]. Water flux, contaminant rejection, and chemical cleaning were evaluated for a CTA membrane and two TFC membranes. One TFC membrane employed a traditional polyamide surface chemistry, while the other was one of the first surface coated polyamide membranes to be employed in FO. Coday et al. did not focus specifically on identifying changes in membrane surface properties or permeability after exposure to produced water; however, membrane surface characterization after each experiment did suggest a shift in each membrane's physiochemical properties, especially the polyamide TFC membranes. Changes in membrane surface properties were supported by membrane integrity tests during which variations in specific reverse salt flux (SRSF) - the ratio of RSF $\left(J_{s}\right)$ of draw solution (DS) solutes to water flux $\left(J_{w}\right)$ from the feed to the DS-were monitored (Figure 1). The SRSF of the CTA membrane changed minimally after produced water treatment, while significant and equally unique trends were recorded for both polyamide TFC membranes (Figure 1a). SRSF increased on average by $74 \%$ for TFC1 and decreased by $39 \%$ for TFC2. While irreversible fouling and cake enhanced concentration polarization (CECP) might have biased these changes in membrane performance (as suggested by the 
relatively large standard deviation shown for TFC1), integrity tests conducted after chemical cleaning (Figure 1b) revealed that changes in membrane performance could possibly be a direct result of chemically or physically induced changes to the membrane. No direct correlation could be established between system operating conditions and the observed changes in membrane performance after exposure to produced water.
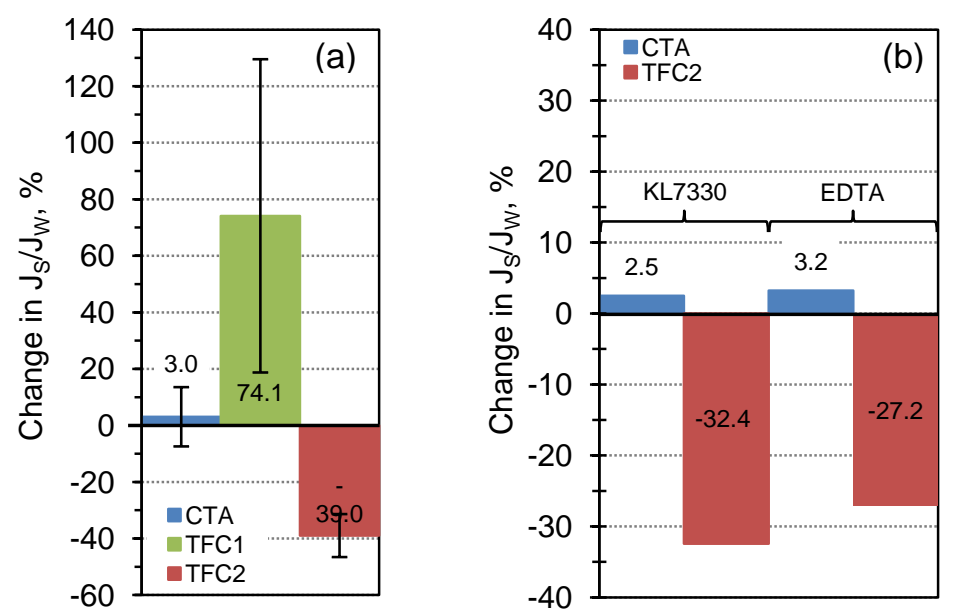

Figure 1. Percent change in $\operatorname{SRSF}\left(\Delta \mathrm{J}_{\mathrm{S}} / \mathrm{J}_{\mathrm{W}}\right)$ of CTA, TFC1, and TFC2 membrane coupons exposed to produced water (48 hrs) and after (a) osmotic backwashing (30 min) and (b) chemical cleaning (30 min). The percent change in SRSF is relative to virgin membrane performance before exposure to produced water. Data adopted from [9].

\subsection{Objectives}

The main objective of this study was to investigate the impacts of exposure to produced water on the transport and physiochemical properties of FO membranes. This study was not meant to supplement the fouling performance and data previously presented for produced water treatment [9], but to elucidate the impact of oil and gas wastewater on the short-term chemical stability of FO membranes. Of special interest was the performance and sustainability of a TFC membrane coated with a proprietary hydrogel to enhance its physical robustness and antifouling properties. A set of bench-scale experiments were conducted using raw produced water feed and three FO membranes, each exhibiting unique surface properties and polymeric chemistries. Each membrane was exposed to produced water for an extended period of time and then thoroughly cleaned prior to membrane autopsy. Integrity testing water flux (deionized water feed), RSF, and membrane surface properties were evaluated before and after exposure to produced water to highlight changes in membrane performance and permeability. An FO transport and structural parameter model [20] and containment rejection data collected during membrane exposure tests support the findings of this investigation. The results of this study can help guide future investigations on the performance and sustainability of polymeric membranes for produced water 
treatment and highlight the need for more rigorous membrane performance testing after fouling studies at the bench-scale.

\section{Materials and methods}

\subsection{FO membranes}

One asymmetric CTA membrane and two polyamide TFC membranes were investigated (Hydration Technology Innovations (HTI), Albany, OR). The first TFC membrane (designated TFC1) is a traditional polyamide membrane with no surface modification, while the active layer of the second TFC membrane (designated TFC2) was modified by HTI with a proprietary hydrogel to enhance its antifouling properties. The support layer of both TFC membranes are reported to be made of polysulfone. Membrane coupons were soaked in deionized water for $24 \mathrm{hrs}$ prior to all experiments and then installed in each test cell with their active layer facing the feed. The water and solute permeability coefficients ( $A$ and $B$, respectively) and the modeled structural parameter $(S)$ of the three membranes were determined using methodologies developed by Tiraferri et al. [20]. The A, B, and S coefficients for each membrane were similar to those reported in our previous study [9], which employed membranes from the same casting. All coefficients of determination $\left(R^{2}\right)$ and coefficients of variation (CV) supporting the validity of the modeled results are summarized in Table 1.

Table 1. CTA membrane physiochemical surface

\begin{tabular}{lcccccc}
\hline \multirow{2}{*}{$\begin{array}{l}\text { Surface } \\
\text { property }\end{array}$} & \multicolumn{2}{c}{ CTA } & \multicolumn{2}{c}{ TFC1 } & \multicolumn{2}{c}{ TFC2 } \\
\cline { 2 - 7 } CV & Virgin & PW & Virgin & PW & Virgin & PW \\
$\mathrm{R}^{2}-J_{W}$ & 1.95 & 3.50 & 1.92 & 8.75 & 10.46 & 9.54 \\
$\mathrm{R}^{2}-J_{S}$ & 0.995 & 0.991 & 0.995 & 0.975 & 0.975 & 0.980 \\
\hline
\end{tabular}

\subsection{Bench-scale FO system}

The bench-scale system and custom-made membrane test cell $\left(194 \mathrm{~cm}^{2}\right.$ active area) used in this investigation are the same as those used in our previous study [9] and have been thoroughly described elsewhere [27]. Three layers of a commercially available tricot spacer were used in the DS flow channel in all experiments to provide mechanical support for the membranes and to minimize physical stress on the membrane at the internal edges of the test cell. LabView data acquisition software (National Instruments, Austin, TX) coupled with UE-9 Pro DAQ hardware (LabJack, Lakewood, CO) were used to control experimental test conditions and to log experimental data.

\subsection{Solution chemistries}

The feed solution used in this study was a comingled O\&G wastewater from the Denver-Julesburg basin consisting of produced water influenced by hydraulic fracturing flowback water (designated produced water in this study). The produced water originated from the Niobrara Shale formation and is 
similar to that previously investigated using the same FO membranes [9]. To minimize chemical variability in feed water quality, produced water were collected in a single sampling event and stored in a $200 \mathrm{~L}$ (55 gal) drum; the drum remained sealed throughout the study in a climate-controlled laboratory. The concentrations of major constituents measured in the produced water are summarized in Table 2.

The DS was prepared using ACS grade $\mathrm{NaCl}$ (Fisher Scientific). During baseline performance tests, four DS concentrations were employed $(0.3,0.6,0.9$, and $1.4 \mathrm{M} \mathrm{NaCl})$ using similar methodologies described by Tiraferri et al. [20]. DS concentrations up to $1.4 \mathrm{M}$ were employed to simulate realistic DS concentrations that can be maintained by a downstream RO process. The evaluation of water flux and RSF at increasing DS concentrations can also help to determine changes in internal concentration polarization (ICP), and thus the structural parameter (S) of each membrane. During experiments in which the membranes were exposed to produced water feed, $1 \mathrm{M} \mathrm{NaCl}$ DS was employed to mimic conditions employed in our previous study [9, 28]. Ethylenediamine-tetraacetic acid (EDTA) (Avantor, Central Valley, PA) was used for cleaning of the membranes after exposure to produced water. The EDTA solution strength was $11,000 \mathrm{mg} / \mathrm{L}$ following manufacturer recommendations and the $\mathrm{pH}$ was adjusted to 8 and 11 for the CTA and TFC membranes, respectively.

Table 2. Average concentrations of major constituents measured in the Niobrara shale produced water.

\begin{tabular}{lr}
\hline Constituent & $\mathrm{mg} / \mathrm{L}$ \\
\hline $\mathrm{pH}$ & 7.2 \\
Total suspended solids & 95 \\
Chemical oxygen demand & 833 \\
Total organic carbon & 320 \\
Dissolved organic carbon & 312 \\
Total nitrogen & 19 \\
Total carbohydrates (guar) & 55 \\
Alkalinity (as CaCO3) & 696 \\
Total dissolved solids (TDS) ${ }^{\mathrm{a}}$ & 15,612 \\
Fluoride & 23 \\
Chloride & 9590 \\
Bromide & 58 \\
Barium & 2.1 \\
Calcium & 57 \\
Magnesium & 14 \\
Lithium & 4.9 \\
Potassium & 589 \\
Iron & 3.1 \\
Manganese & 0.14 \\
Sodium & 5,233 \\
Phosphorous & 0.34 \\
Strontium & 4.2 \\
\hline a $\Sigma$ Cations = 247.7 meq/L; $\Sigma$ Anions = 272.4 meq/L
\end{tabular}

\subsection{Experimental procedures}




\subsubsection{Baseline membrane performance verification}

All baseline membrane performance tests were conducted with $1 \mathrm{~L}$ (initial volume) DS $(0.3,0.6,0.9$, and $1.4 \mathrm{M} \mathrm{NaCl}$ ) and $3 \mathrm{~L}$ deionized water feed at constant temperature $\left(20{ }^{\circ} \mathrm{C}\right)$. The DS concentration and feed volume were held constant by intermittent dosing of $300 \mathrm{~g} / \mathrm{L} \mathrm{NaCl}$ solution into the DS tank and deionized water into the feed tank. For the first set of baseline experiments, a new membrane coupon was installed in the test cell and its performance (i.e., water flux and RSF) was evaluated for $1.5 \mathrm{hrs}$ using $0.3 \mathrm{M} \mathrm{NaCl}$ DS. The feed and DS cross-flow velocity was $0.2 \mathrm{~m} / \mathrm{s}$ with a transmembrane pressure (TMP) of less than $0.07 \mathrm{bar}(1 \mathrm{psi})$ in favor of the feed. After $1.5 \mathrm{hrs}$ the system was stopped, drained, and the DS was replaced with $0.6 \mathrm{M} \mathrm{NaCl}$ DS. The feed tank was filled with new deionized water. Baseline performance tests resumed under the same testing conditions for another $1.5 \mathrm{hrs}$. This procedure was repeated for two additional experiments using $0.9 \mathrm{M}$ and $1.4 \mathrm{M} \mathrm{NaCl} \mathrm{DS}$. At the end of the experiment, all streams were flushed with deionized water and the system was left to recirculate for $12 \mathrm{hrs}$. After recirculation, the virgin membrane coupons were removed from the system and stored for autopsy; half of each coupon was dried in a desiccator and half was stored wet at $5 \stackrel{\circ}{\circ}$.

After evaluating each virgin membrane's performance, a new membrane coupon was installed in the test cell and the performance experiments were repeated with the same four DS concentrations and deionized water feed; however, at the end of the experiments the membrane coupons were not removed from the system. Instead, the system was drained and the feed was replaced with EDTA solution and the DS was replaced with deionized water. The solutions were circulated in the system for $2 \mathrm{hrs}$ at $0.2 \mathrm{~m} / \mathrm{s}$ in both hydraulic channels and with 0.07 bar TMP, simulating chemically enhanced osmotic backwashing (CEOB). After 2 hrs of CEOB, the system was stopped and all hydraulic channels were replaced with deionized water for $12 \mathrm{hrs}$ of continuous recirculation to rinse the membrane and test system of EDTA. After $12 \mathrm{hrs}$ of deionized water recirculation, membrane performance test were repeated to determine if changes in baseline membrane performance occurred after CEOB only. At the end of the performance evaluation, the coupons were removed from the system and stored for autopsy.

\subsubsection{Membrane exposure to produced water}

All produced water exposure tests were conducted with $1 \mathrm{~L}$ (initial volume) $\mathrm{DS}(1 \mathrm{M} \mathrm{NaCl})$ and $200 \mathrm{~L}$ of produced water feed at constant temperature $\left(20^{\circ} \mathrm{C}\right)$. The produced water barrel was connected to the membrane test cell in a closed loop, which remained sealed for the duration of the study. A large feed volume ensured that adequate concentrations of membrane foulants and dissolved contaminants were present for the duration of each experiment and that changes in feed stream osmotic pressure were negligible. The DS concentration was held constant by intermittent dosing of $300 \mathrm{~g} / \mathrm{L} \mathrm{NaCl}$ solution into the DS tank. Deionized water was not added to the feed barrel during exposure tests.

Before each produced water exposure test, a new membrane coupon was installed in the test cell and baseline performance experiments were repeated with the same four $\mathrm{NaCl} \mathrm{DS}$ concentrations and deionized water feed. After baseline performance tests were completed, each membrane coupon was 
exposed to produced water for $48 \mathrm{hrs}$ under the same hydrodynamic conditions described above, thereby mimicking the fouling conditions explored in our previous study (feed and DS velocity $0.2 \mathrm{~m} / \mathrm{s}$, TMP 0.07 bar, no feed spacer) [9]. Exclusion of turbulence enhancing spacer in the feed channel during these experiments ensured that changes in membrane performance after exposure to produced water were not due to physical deformations of the active layer at the spacer-membrane interface. After $48 \mathrm{hrs}$ of produced water exposure the system was stopped, the feed and DS channels were drained, and the membrane coupon was cleaned by CEOB for 2 hrs. Although no foulants were visible on the membranes after $\mathrm{CEOB}$, the flow channels of the system were drained and replaced with deionized water on both sides of the membrane and the system was left to recirculate for $12 \mathrm{hrs}$. This allowed ample time for any contaminants remaining on the membrane surface to potentially solubilize into the deionized water. After $12 \mathrm{hrs}$ recirculation of deionized water, membrane performance test were repeated to determine if changes in baseline membrane performance occurred after exposure to produced water. At the end of the performance evaluation, the coupons were removed from the system and stored for autopsy.

\subsection{Sampling and analytical methods}

Cation concentrations in the feed and DS were analyzed using inductively coupled plasma atomic emission spectroscopy (ICP-AES, Standard Method 3120 B) (Optima 5400, PerkinElmer, Fremont, CA) and anion concentrations were analyzed using ion chromatography (IC, Standard Method 4110 B) (ICS90, Dionex, Sunnyvale, CA). All samples were diluted as necessary to bring sodium and chloride concentrations below $500 \mathrm{mg} / \mathrm{L}$ and feed samples were filtered through a $0.45 \mu \mathrm{m}$ filter to remove suspended particles. For ICP-AES analyses, samples were acidified with nitric acid to below pH 2. Feed samples were also analyzed for alkalinity, hardness, and total carbohydrate concentration; carbohydrate concentrations were quantified using the anthrone method [29]. It can be assumed that carbohydrates in the feed were attributed to guar gum, which is commonly used as a viscosity enhancer to suspend proppants during hydraulic fracturing [30].

A Shimadzu TOC-L carbon analyzer (Shimadzu Corporation, Columbia, MD) using a combustion catalytic oxidation method was used to quantify total organic carbon (TOC), dissolved organic carbon (DOC), and total nitrogen (TN) concentrations. Samples were acidified using hydrochloric acid to below $\mathrm{pH}$ 2. A non-targeted screening of organic compounds in the feed and DS was conducted using accuratemass liquid chromatography-quadrupole time-of-flight ((LC/Q-TOF) Agilent 6540, Santa Clara, CA) and gas chromatography-quadrupole time-of-flight ((GC/Q-TOF) Agilent 7200, Santa Clara, CA) mass spectrometry analyses. LC- and GC/Q-TOF were used to qualitatively evaluate the prevalence and distribution of dissolved organic compounds in the produced water feed and of the organic compounds that diffused through the FO membranes into the DS.

Separation for LC/Q-TOF analysis was performed on a Zorbax C18 column using a water/acetonitrile gradient with formic acid as modifier at a flow of $0.4 \mathrm{~mL} / \mathrm{min}$ [31]. For each run, $10 \mu \mathrm{L}$ sample was injected in triplicate. The gradient was held constant at $90 \%$ water and $10 \%$ acetonitrile for the first 
minute. The percentage of acetonitrile was then constantly increased to reach $100 \%$ at 10 min, which was held for $5 \mathrm{~min}$. The first minute of each run was diverted to waste to avoid the introduction of large amounts of salt into the instrument. ESI positive mode was used with a scan range from $\mathrm{m} / \mathrm{z} 25$ to $\mathrm{m} / \mathrm{z}$ 3200.

$10 \mathrm{~mL}$ samples for GC/Q-TOF analysis were placed into $20 \mathrm{~mL}$ vials. A SPME fiber (30 $\mu \mathrm{m}$ PDMS) was exposed to the headspace above the sample for $10 \mathrm{~min}$, while the sample was heated to $60{ }^{\circ} \mathrm{C}$. Desorption of the compounds from the SPME fiber occurred immediately afterwards in the GC injector at $250^{\circ} \mathrm{C}$. Separation for GC/Q-TOF analysis was performed on a $30 \mathrm{~m}$ HP-5ms Agilent column $(0.25 \mathrm{~mm} \mathrm{x}$

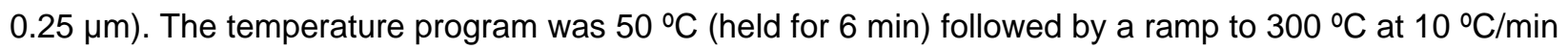
(held for $10 \mathrm{~min}$ ). Electron ionization mode at $70 \mathrm{eV}$ was used with a scan range of $\mathrm{m} / \mathrm{z} 40$ to $1000 \mathrm{Da}$. All samples were injected in triplicate.

LC/Q-TOF data was processed using Mass Profinder (Agilent Technologies) to identify molecular features that appeared in all of the triplicates of each sample, followed by Mass Profiler Professional (MPP - Agilent Technologies) for alignment and identification of similar and unique features in each sample. GC/Q-TOF data was deconvoluted using MassHunter Qual (Agilent). Mass Profiler Professional was used for alignment and identification of compound features that were only present in all triplicates of each sample. Heat maps were generated in Mass Profiler Professional after the subtractions of method blanks from each sample.

\subsection{Membrane characterization}

The active layer of each FO membrane before (virgin) and after exposure to EDTA cleaning solution and produced water was analyzed using several traditional membrane characterization techniques. The goal was not to identify the unique physiochemical properties of each membrane surface, but rather to elucidate changes to the polymeric surface of the FO membranes after exposure to produced water.

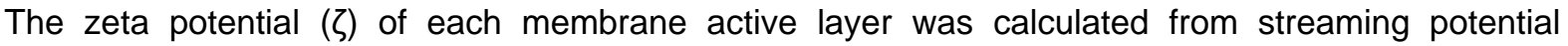
measurements conducted on an electrokinetic analyzer (SurPASS, Anton Paar GmbH, Austria). Streaming potential measurements were conducted using $2 \mathrm{mM} \mathrm{KCl}$ electrolyte solution at room temperature and $\mathrm{pH}$ range of 3 to $9(\mathrm{pH} 4$ to 8 for CTA). Further information on the streaming potential measurements and the calculation of zeta potential can be found elsewhere [9, 32, 33]. The surface energy parameters and hydrophobicity of each membrane active layer were calculated from captive bubble contact angle measurements using a goniometer (Rame-Hart Inc., Mountain Lakes, NJ). Contact angle measurements were conducted at ambient conditions with deionized water, diiodomethane ( $\geq 99 \%$, Sigma-Aldrich), and glycerol ( $\geq 99 \%$, Sigma-Aldrich) reference solutions. No less than ten contact angle measurements were recorded for each membrane at steady state (1 min of interfacial contact) using a 10 $\mu \mathrm{L}$ air bubble and then the average contact angle was calculate. The averaged contact angle

measurements using the three reference solutions were used to calculate the surface energetics (i.e., $\gamma^{\mathrm{LW}}$, $\bar{\gamma}, \gamma^{+}$, and $\Delta \mathrm{G}_{\mathrm{sws}}$ ) of each membrane using the Lifshitz-van der Waals acid-base approach following 
procedures outlined elsewhere [9, 34, 35]. Attenuated Total Reflectance Fourier Transform Infrared Spectroscopy (ATR-FTIR) analysis was conducted on each membrane active layer using a Nicolet IS50 FTIR spectrometer (Thermo Scientific, Madison WI) fitted with a diamond crystal ATR accessory and coupled with a DTGS detector. Transmission spectra were measured using 10 scans at resolution 4 $\left(0.482 \mathrm{~cm}^{-1}\right)$ and then adjusted by subtracting a background spectrum (measured prior to each membrane) from the membrane spectrum using an Omnic analysis software package (Thermo Scientific).

\section{Results and discussion}

\subsection{Membrane performance and transport properties}

Integrity testing water flux (deionized water feed) and RSF were calculated for each virgin membrane after $\mathrm{CEOB}$ only and after produced water exposure followed by CEOB. While membrane fouling investigation was beyond the scope of this study, the order of water flux (TFC2>TFC1>CTA), rate of flux decline, and fouling mechanisms of each membrane during produced water exposure were similar to those described in our previous investigation (data not shown) [9]. The measured and calculated physiochemical properties of each membrane are compared before and after solution exposure experiments; contaminant rejection data from produced water exposure tests are also calculated and discussed below.

\subsubsection{CTA membrane: characteristics and transport properties}

CTA membrane performance and surface characterization results are shown in Figure 2. Integrity testing water flux and RSF as a function of DS concentration during baseline testing are shown in Figure 2a. Solid symbols represent baseline data obtained using a virgin membrane coupon (designated pre exposure) and empty symbols represent data collected after CEOB only (designated post exposure). A similar graph showing changes in membrane performance after exposure to produced water and CEOB is shown in Figure $2 \mathrm{~b}$. FTIR spectra obtained from each membrane coupon and zeta potential as a function of electrolyte $(2 \mathrm{mM} \mathrm{KCl}) \mathrm{pH}$ are shown in Figure $2 \mathrm{c}$ and $2 \mathrm{~d}$, respectively. The transport and structural parameters, and surface energetic values calculated for each CTA membrane are summarized in Table 3. 

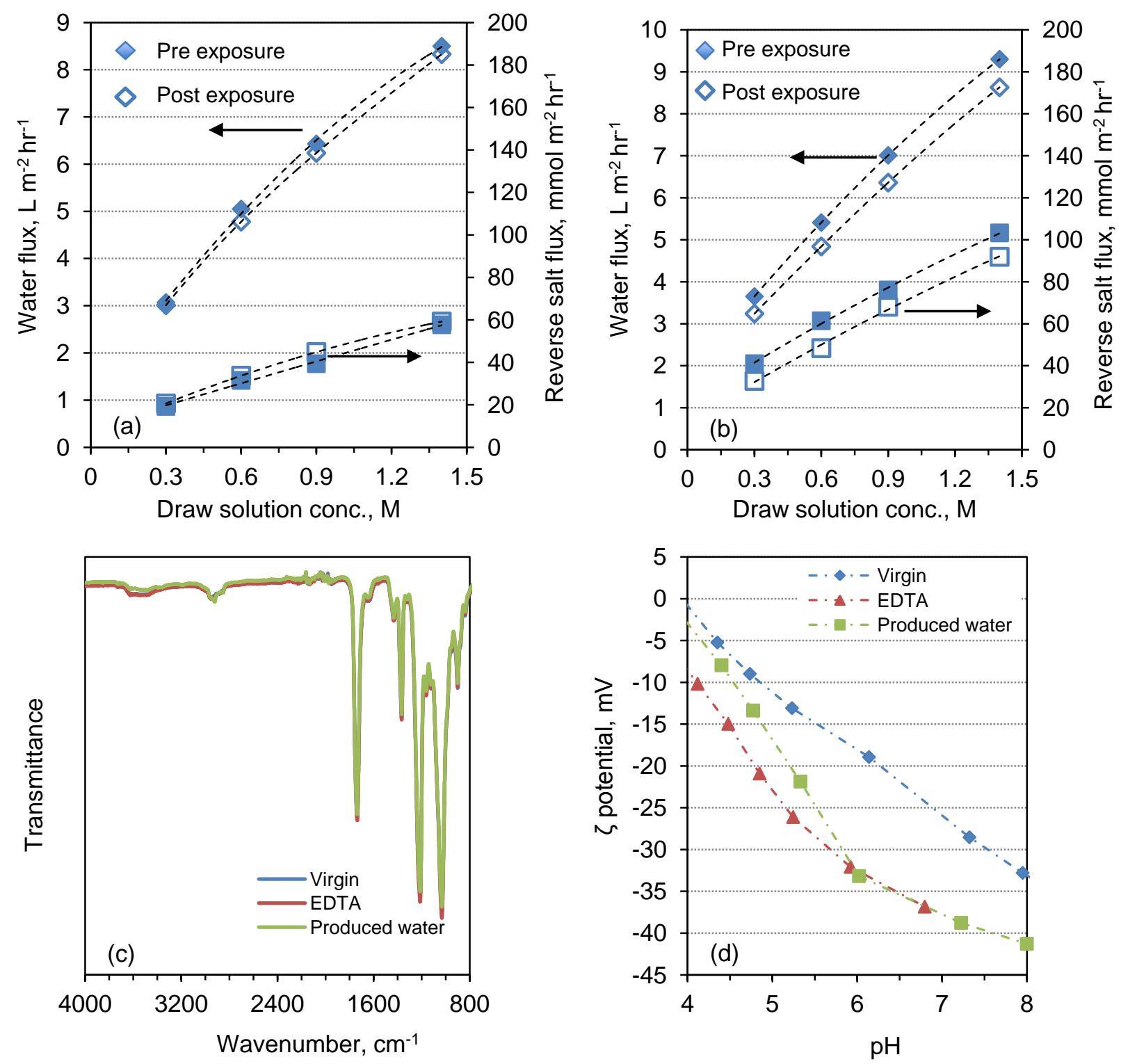

Figure 2. Membrane performance is compared for (a) virgin CTA membranes before and after exposure to EDTA for 2 hrs and for (b) virgin CTA membranes before and after exposure to produced water and CEOB with EDTA. (c) FTIR spectra and (d) zeta potential of CTA membrane coupons are also compared to identify differences in the chemical and electrokinetic properties of each membrane following exposure to cleaning and feed solutions.

Water flux and RSF through the CTA membrane were unchanged after CEOB only (Figure 2a), indicating that $2 \mathrm{hrs}$ of exposure to EDTA at $\mathrm{pH} 8$ might impart minimal or no change in membrane performance when employed for membrane cleaning. After the CTA membrane was exposed to produced water and chemically cleaned, deionized feed water flux decreased on average by $10 \%$ and RSF decreased by close to $16 \%$ (Figure $2 \mathrm{~b}$ ). Despite changes to the membrane's water permeability, no changes in the chemical properties of the membrane were identified by FTIR (Figure 2c). The electrokinetic properties of the CTA membrane also remained relatively unchanged. Membrane zeta 
potential became slightly more negative after COEB, indicating that EDTA likely removed manufacturing chemicals sorbed to the membrane surface after casting; however, no further changes were observed after exposure to produced water. The changes in water permeability, and minimal differences between the chemical and electrokinetic properties of the membrane coupons suggest that the transport parameters of the CTA selective layer might have decreased. The structural parameter of the CTA membrane might have also changed, thereby influencing ICP. Using these experimental data, the potential changes in the CTA transport and structural parameters were modeled using the FO method [20], and results are summarized in Table 3.

The water permeability coefficient $(A)$ of the CTA membrane declined from $0.339 \mathrm{LMH} / \mathrm{bar}$ to 0.254 $\mathrm{LMH} /$ bar and the salt permeability coefficient $(B)$ declined from $0.183 \mathrm{LMH}$ to $0.131 \mathrm{LMH}$; however, the ratio of the membrane's $B$ coefficient to $A$ coefficient remained nearly constant. Several reasons for decreased CTA permeability, besides membrane fouling, have been proposed in the literature. One possibility is osmotically induced de-swelling or dehydration of the CTA polymer chains when exposed to the high ionic strength feed and DS streams, thereby irreversibly decreasing water and solute permeability $[36,37]$. Charge neutralization within the membrane matrix has also been proposed, where increasing ionic strength near the membrane polymers can effectively shield their charge density and minimize electrostatic repulsion [36]. A reduction in electrostatic repulsion between the polymer chains can compact the already dense membrane active layer and decrease water and solute permeability. In a recent study [32] we have shown that increasing ionic strength at a membrane-solution interface can shield the membrane's charge density and reduce its zeta potential by nearly $75 \%$. The irreversible sorption of divalent counterions within the polymer matrix can also exacerbate charge neutralization and de-swelling. Another plausible scenario is the entrapment or sorption of dissolved constituents within the polymer matrix, which can hinder the diffusion of water, and especially other solutes, through the membrane [38]. The virgin CTA membrane is slightly hydrophobic as shown by the moderate contact angle and negative free energy of interaction $\left(\Delta G_{s w s}\right)$ value in Table 3, which might promote the sorption of hydrophobic contaminants and hydrocarbons to the CTA polymer chains of the active layer and retard solvent and solute diffusion.

In addition to the decrease in CTA transport properties, its modeled structural parameter also decreased from $533 \mu \mathrm{m}$ to $433 \mu \mathrm{m}$ after exposure to produced water. While the intrinsic structural parameter of the membrane (i.e., contribution of tortuosity, thickness, and porosity of the support layer) likely remained unchanged, its modeled structural parameter has decreased due to pore wetting and changes in hydrophilicity within the support layer. Interestingly, the hydrophilicity of the CTA active layer increased after exposure to produced water, which likely resulted from changes in the membrane's polar (acid-base) properties; the electron acceptor component $\left(\gamma^{+}\right)$of the membrane decreased, while its electron donor component $\left(\gamma^{-}\right)$increased. Because the membrane is asymmetric and only composed of CTA polymer, a similar shift in polar properties and hydrophilicity likely occurred in the porous substructure of the CTA support over the $48 \mathrm{hr}$ exposure test. The increased wetting efficiency due to 
greater hydrophilicity within the support layer could explain the decrease in the modeled structural parameter of the post exposure membrane compared to virgin coupons. A decrease in the modeled structural parameter of the CTA membrane should minimize dilutive ICP; however, the decline in solute and water permeability of the CTA active layer was of greater significance. Therefore, overall, water flux and RSF did not increase.

Table 3. CTA membrane physiochemical surface properties

\begin{tabular}{|c|c|c|c|}
\hline \multirow{2}{*}{ Surface property } & \multicolumn{3}{|c|}{ CTA } \\
\hline & Virgin & EDTA $^{c}$ & $\mathrm{PW}^{\mathrm{d}}$ \\
\hline $\mathrm{A}\left(\mathrm{L} \mathrm{m}^{-2} \mathrm{hr}^{-1} \mathrm{bar}^{-1}\right)$ & 0.339 & - & 0.254 \\
\hline$B\left(\mathrm{~L} \mathrm{~m}^{-2} h r^{-1}\right)$ & 0.183 & - & 0.131 \\
\hline$S(\mu \mathrm{m})$ & 533 & - & 433 \\
\hline $\mathrm{CV}^{\mathrm{a}}$ & 1.95 & - & 3.50 \\
\hline$R^{2}-J_{W}$ & 0.995 & - & 0.991 \\
\hline$R^{2}-J_{S}$ & 0.989 & - & 0.990 \\
\hline Contact angle ${ }^{\mathrm{b}},\left(^{\circ}\right)$ & $48.2 \pm 2.6$ & $47.0 \pm 2.1$ & $38.8 \pm 2.4$ \\
\hline$\Delta \mathrm{G}_{\mathrm{sws}}\left(\mathrm{mJ} / \mathrm{m}^{2}\right)$ & -0.9 & -2.2 & 8.5 \\
\hline$\gamma^{L W}\left(\mathrm{~mJ} / \mathrm{m}^{2}\right)$ & 37.1 & 38.4 & 44.5 \\
\hline$\gamma^{+}\left(\mathrm{mJ} / \mathrm{m}^{2}\right)$ & 1.3 & 1.4 & 0.44 \\
\hline$\gamma^{-}\left(\mathrm{mJ} / \mathrm{m}^{2}\right)$ & 27.6 & 27.1 & 35.89 \\
\hline
\end{tabular}

${ }^{a} \mathrm{CV}$ is the coefficient of variation of $\mathrm{J}_{\mathrm{w}} / \mathrm{J}_{\mathrm{s}}$. CV is defined as the standard deviation divided by the arithmetic mean.

${ }^{\mathrm{b}}$ Deionized water using captive bubble method

${ }^{c}$ FO modeling was conducted on membrane coupons exposed to produced water

${ }^{\mathrm{d}}$ Produced water

It is important to note that despite slight changes in membrane performance post exposure, the average SRSF of the CTA membrane remained relatively unchanged $(10.4 \pm 0.4 \mathrm{mM} / \mathrm{L})$ compared to the virgin membrane coupon $(11.1 \pm 0.1 \mathrm{mM} / \mathrm{L})$. These findings are analogous to the changes in CTA membrane performance observed in our previous study [9] (Figure 1a and 1b), and suggest that the CTA membranes might experience some repeatable, albeit minimal, changes in polymer characteristics when exposed to produced waters.

\subsubsection{Polyamide TFC membrane: characteristics and transport properties}

The performance and surface characterization results of the TFC1 membrane are shown in Figure 3. Deionized feed water flux and RSF as a function of DS concentration during baseline testing are shown in Figure $3 \mathrm{a}$, and the changes in membrane performance after exposure to produced water and CEOB are shown in Figure 3b. FTIR spectra obtained from the membrane coupons and zeta potential curves as a function of electrolyte $\mathrm{pH}$ are shown in Figure $3 \mathrm{c}$ and $3 \mathrm{~d}$, respectively. The transport and structural parameters, and the surface energetic values calculated for each TFC1 membrane are summarized in Table 4.

Similar to the CTA membrane, water flux and RSF through TFC1 were unchanged after CEOB (Figure 3a); however, water flux and RSF were slightly higher after exposure to produced water, 
especially at higher DS concentrations (Figure 3b). When tested with $0.3 \mathrm{M}$ and $0.6 \mathrm{M} \mathrm{NaCl} \mathrm{DS}$, the membrane behaved similarly with almost no change in performance between pre and post exposure to EDTA. With increasing DS concentration the membrane performance, and especially the RSF, began to deviate from that of the virgin membrane. When tested with $1.4 \mathrm{M} \mathrm{NaCl} \mathrm{DS,} \mathrm{RSF}$ increased by close to $20 \%$, while water flux only increased by $4.5 \%$. Despite changes in the membrane's performance when tested with deionized feed, no significant changes in the chemical or electrokinetic properties of the membrane were identified by FTIR analyses or zeta potential calculations (Figure $3 \mathrm{c}$ and $3 \mathrm{~d}$, respectively). Given the changes in water flux and RSF with minimal change in the membrane's chemical and electrokinetic properties, it is possible that increasing RSF at higher DS concentrations was due to reduced ICP, resulting from changes in the membrane's structural parameter. Using these experimental data, the potential changes in the TFC1 transport and structural parameters were determined using the FO modeling method [20] (Table 3).

The water permeability coefficient $(A)$ of the TFC1 membrane declined from $1.39 \mathrm{LMH} / \mathrm{bar}$ to 0.807 $\mathrm{LMH} /$ bar and its salt permeability coefficient $(B)$ declined from $0.639 \mathrm{LMH}$ to $0.398 \mathrm{LMH}$. Similar to the CTA membrane, the ratio of the membrane's $B$ coefficient to $A$ coefficient remained nearly constant, indicating that the membrane has not changed. Similar phenomena resulting in decreased TFC1 permeability compared to CTA are possible. These include osmotically induced de-swelling or dehydration of the polyamide polymer chains when exposed to the high ionic strength produced water and $\mathrm{NaCl} \mathrm{DS}$, compacting the membrane selective layer $[39,40]$. ENREF 36 Membrane hysteresis, resulting from cyclic swelling and de-swelling of the TFC membrane, is a possible phenomena that has been used to describe increasing solute rejection and lower water permeability of polyamide membranes [41]. Cyclic swelling and de-swelling of the membrane would occur in produced water treatment during operation of the TFC1 membrane and its subsequent cleaning cycles over its service life. Charge neutralization within the membrane selective layer and between the polymer chains is also possible, especially considering the ionizable nature of the TFC1 membrane [40]. According to the Donnan theory, increasing presence or density of ionizable groups and electrokinetic phenomena in the polymer matrix can accentuate membrane de-swelling [42, 43]. This could explain why the apparent compaction of TFC1's selective layer was greater than that of the CTA's; the CTA membrane has been described in recent literature as lacking an ionizable polymeric surface, while the ionizable characteristics of polyamide membranes are well know [32]. Hindered diffusion through the TFC active layer due to contaminant sorption and entrapment within the selective layer might also occur concurrently with membrane deswelling. However, the low contact angle and positive free energy of interaction $\left(\Delta G_{S w s}\right)$ values provided in Table 4 suggest that the TFC membrane is very hydrophilic and will likely experience far less contaminant sorption within the polymer matrix than the CTA. Curiously, the hydrophilicity and polar surface properties of the TFC membrane remained relatively unchanged after exposure to produced water and did not increase as observed with the CTA membrane. This suggests a low probability that 
hydrophobic or polar compounds that might have sorbed to the membrane surface significantly impacted the performance of TFC1 and its surface properties.
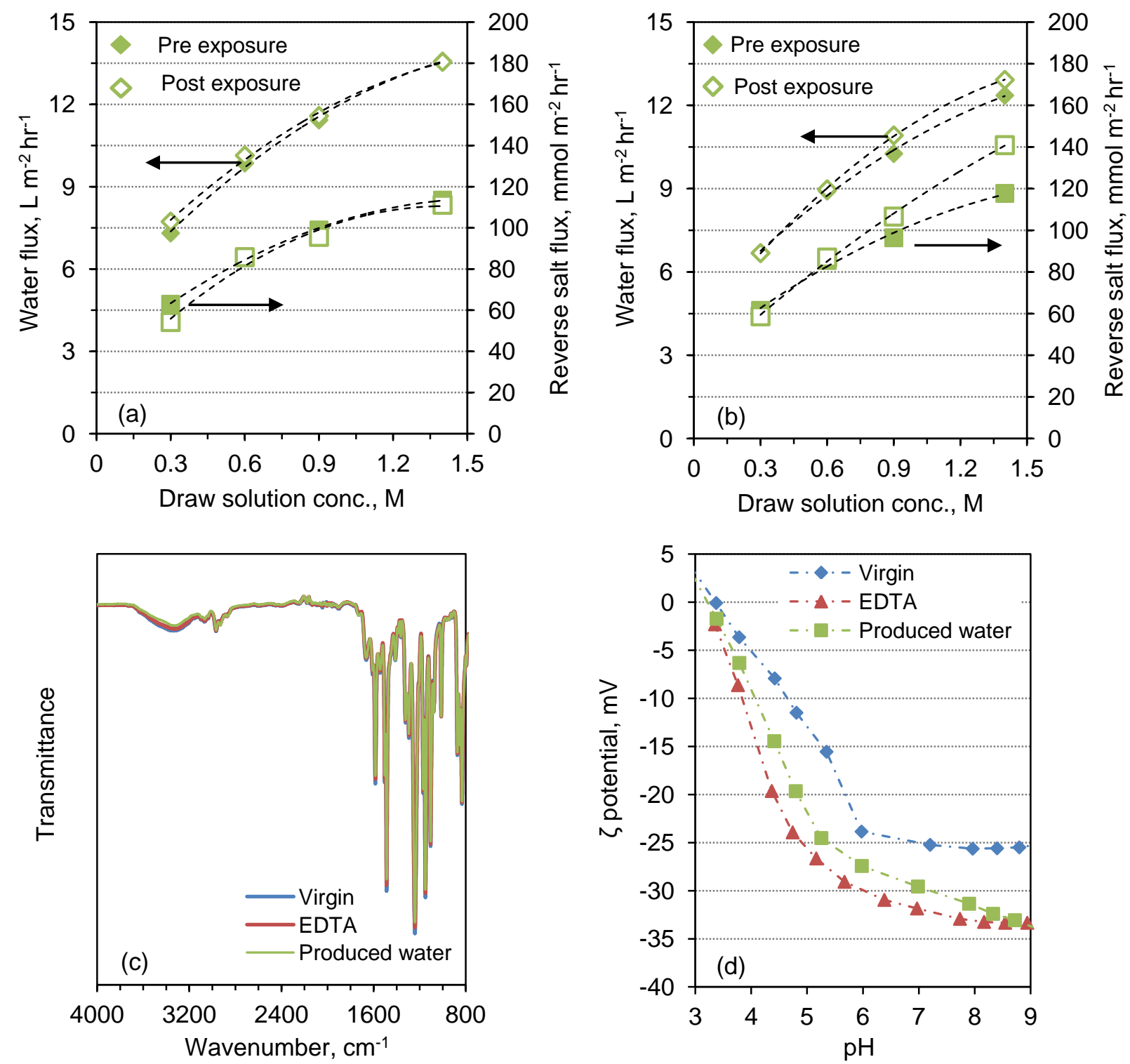

Figure 3. Membrane performance is compared for (a) virgin TFC1 membranes before and after exposure to EDTA for $2 \mathrm{hrs}$ and for (b) virgin TFC1 membranes before and after exposure to produced water and CEOB with EDTA. (c) FTIR spectra and (d) zeta potential of TFC1 membrane coupons are also compared to identify differences in the chemical and electrokinetic properties of each membrane following exposure to cleaning and feed solutions.

It is interesting to note that higher RSF and water flux were observed during FO experiments at increasing DS concentration, despite a modeled decrease in the membrane permeability. In fact, this phenomenon is not completely unexpected and indicates increased osmotic pressure and solute concentration within the membrane's porous support layer. An increase in the solute concentration 
difference across the TFC active layer can occur given an appropriate decrease in the structural parameter of the membrane, thereby decreasing the effects of dilutive ICP. This in fact does occur based on FO modeling, where the TFC structural parameter decreased from $868 \mu \mathrm{m}$ to $563 \mu \mathrm{m}$ after exposure to produced water. One possible reason for the change in the modeled structural parameter of the membrane could be enhanced pore wetting and changes in hydrophilicity within the TFC support layer. The effects of TFC support layer wetting on TFC membrane performance has been previously investigated $[44,45]$, where complete or enhanced pore wetting can reduce the effects of dilutive ICP by increasing DS continuity within the TFC membrane. A decrease in the intrinsic structural parameter (i.e., support layer thickness) might also occur in the TFC membrane due to electrostatic charge shielding between the polymer chains and subsequent compaction of the membrane support. Yet, the effects of support layer compaction on tortuosity and porosity remain unknown.

Table 4. TFC1 membrane physiochemical surface properties

\begin{tabular}{lccc}
\hline \multirow{2}{*}{ Surface property } & \multicolumn{3}{c}{ TFC1 } \\
\cline { 2 - 4 } & Virgin & $E^{\mathrm{C} T A^{\mathrm{C}}}$ & $\mathrm{PW}^{\mathrm{d}}$ \\
\hline $\mathrm{A}\left(\mathrm{L} \mathrm{m}^{-2} \mathrm{hr}^{-1} \mathrm{bar}^{-1}\right)$ & 1.39 & - & 0.807 \\
$\mathrm{~B}\left(\mathrm{~L} \mathrm{~m}^{-2} \mathrm{hr}^{-1}\right)$ & 0.639 & - & 0.398 \\
$\mathrm{~S}(\mu \mathrm{m})$ & 868 & - & 563 \\
$\mathrm{CV}$ & 1.92 & - & 8.75 \\
$\mathrm{R}^{2}-\mathrm{J}_{\mathrm{W}}$ & 0.995 & - & 0.975 \\
$\mathrm{R}^{2}-\mathrm{J}_{\mathrm{S}}$ & 0.993 & - & 0.979 \\
$\mathrm{Contact} \mathrm{angle}^{\mathrm{b}},\left(^{\circ}\right)$ & $19.8 \pm 3.8$ & $18.2 \pm 3.5$ & $15.8 \pm 1.9$ \\
$\Delta \mathrm{G}_{\mathrm{sws}}\left(\mathrm{mJ} / \mathrm{m}^{2}\right)$ & 37.4 & 28.6 & 41.12 \\
$\gamma^{\mathrm{W}}\left(\mathrm{mJ} / \mathrm{m}^{2}\right)$ & 34.1 & 35.8 & 38.1 \\
$\gamma^{+}\left(\mathrm{mJ} / \mathrm{m}^{2}\right)$ & 1.1 & 1.8 & 0.6 \\
$\gamma^{-}\left(\mathrm{mJ} / \mathrm{m}^{2}\right)$ & 57.1 & 51.8 & 59.3 \\
\hline
\end{tabular}

${ }^{a} \mathrm{CV}$ is the coefficient of variation of $\mathrm{J}_{\mathrm{w}} / \mathrm{J}_{\mathrm{s}}$. CV is defined as the standard deviation divided by the arithmetic mean.

${ }^{\mathrm{b}}$ Deionized water using captive bubble method

${ }^{c}$ FO modeling was conducted on membrane coupons exposed to produced water

${ }^{\mathrm{d}}$ Produced water

Despite the change in membrane performance at higher DS concentrations and decrease in membrane permeability, the average SRSF of the TFC1 membrane remained similar $(9.8 \pm 0.9 \mathrm{mM} / \mathrm{L})$ to the virgin membrane coupon $(9.4 \pm 0.2 \mathrm{mM} / \mathrm{L})$. These are encouraging findings considering the overwhelming increase in TFC1 SRSF observed in our previous study (Figure 1a). The minimal changes in TFC1 membrane performance indicate that this membrane might be more chemically and physically compatible with produced water than data suggests in Figure 1a-we can now say with reasonable confidence that the high SRSF was largely attributed to lower water flux through TFC1 resulting from irreversible fouling after un-optimized cleaning with osmotic backwashing. This decrease in water flux substantially reduced ICP within the TFC support layer, thereby increasing RSF. For example, assuming a solute permeability of $0.639 \mathrm{LMH}$, water flux of $10.3 \mathrm{LMH}$, and $0.9 \mathrm{M}$ DS concentration, a $20 \%$ drop in water flux through the virgin TFC1 membrane could result in a $41 \%$ increase in RSF. An additional $10 \%$ 
drop in water flux could further increase the RSF through TFC1 by another $26 \%$. The overall decrease in the modeled structural parameter of the TFC1 membrane after exposure to produced water could further exacerbate this disparity between water flux and RSF, thereby slightly increasing SRSF. Such findings could have significant implications in future cleaning studies employing this TFC membrane for produced water treatment, where the efficiency of membrane cleaning might be optimized based on rapidly increasing RSF as membrane fouling increases over time.

\subsubsection{Surface modified TFC membrane: characteristics and transport properties}

Membrane performance and results from zeta potential calculations and FTIR analyses are shown in Figure 4 for the TFC2 FO membrane. Deionized feed water flux and RSF as a function of DS concentration during baseline testing are shown in Figure $4 \mathrm{a}$ and the changes in membrane performance after exposure to produced water and CEOB are shown in Figure 4b. FTIR spectra obtained from each membrane coupon and zeta potential curves as a function of electrolyte $\mathrm{pH}$ are shown in Figure $4 \mathrm{c}$ and $4 \mathrm{~d}$, respectively. The transport and structural parameters, and surface energetic values calculated for each TFC2 membrane are summarized in Table 5.

TFC2 was the only membrane that exhibited minor changes in water flux and RSF after CEOB (Figure 4a). Water flux through the membrane slightly increased, while the overall dependence of RSF on DS concentration varied marginally. Yet, these changes are minor compared to the membrane performance observed after exposure to produced water. At all DS concentrations investigated, water flux only decreased by $4.4 \%$, while RSF decreased by nearly $50 \%$. Similar to the other FO membranes, the changes in the membrane's performance (when tested with deionized feed) showed no correlation to changes in chemical or electrokinetic properties of the membrane (Figure $4 \mathrm{c}$ and $4 \mathrm{~d}$ ). The FTIR spectra of the TFC2 membrane was slightly suppressed after CEOB, which might indicate the removal of manufacturing chemicals from the active layer and account for the slight changes in membrane performance shown in Figure 4a. Yet, the FTIR spectra of the membrane after exposure to produced water exhibited no further suppression of the transmittance peaks.

The TFC2 deionized feed water permeability coefficient declined from $1.16 \mathrm{LMH} / \mathrm{bar}$ to 0.748 $\mathrm{LMH} /$ bar and the salt permeability coefficient $(B)$ declined from $0.234 \mathrm{LMH}$ to $0.089 \mathrm{LMH}$; however, unlike the CTA and TFC1 membranes, the ratio of the $B$ coefficient to the $A$ coefficient of TFC2 decreased by nearly $40 \%$ after exposure to the produced water. Similar to TFC1, the membrane's modeled structural parameter was also impacted, decreasing from $489 \mu \mathrm{m}$ to $354 \mu \mathrm{m}$. Because the TFC2 membrane is a derivative of TFC1 and their support layers are comparable, changes in the structural parameter were expected- similar reasoning for decreasing in the values of the structural parameter is provided in Section 3.2.2 apply here. Comparable changes in the TFC2 polyamide active layer, present just below the proprietary hydrogel surface coating, might also be expected based on results presented in Section 3.2.2. Yet, the remarkable drop in solute permeability through the membrane cannot be explained 
exclusively by changes in the polyamide active layer and indicates that changes have also occurred, albeit favorably, in the membrane's surface coating.

While the application of surface coating in FO has been largely uninvestigated, commercial reverse osmosis (RO) and nanofiltration (NF) membranes have been coated with a variety of polymers to increase their active layer robustness and antifouling properties [46]. This is most typically achieved by applying a neutral (or near neutral), hydrophilic polymer to the existing membrane's active layer, thereby decreasing the surface roughness of the membranes and minimizing their charge. The properties and permeability of the surface coating are most commonly tuned by crosslinking the chosen polymer through heat treatment, $\gamma$-irradiation, or by use of a variety of different chemical compounds [46]. While the methods of surface coating employed by $\mathrm{HTI}$ are proprietary, the favorable changes expected from surface coating are consistent with TFC2 surface characteristics reported in our previous study [9], where the roughness of the TFC2 membrane was nearly $50 \%$ lower than that of the TFC1 and the CTA. Without a better understanding of the surface coating chemistry or degree of crosslinking in the chosen polymer, it is difficult to comment on the apparent zeta potential and hydrophilicity of TFC2.

Although the exact chemistry of the TFC2 surface coating is not readily available, the significant increase in the membrane's solute rejection could be due to a shift in the crosslinking density of the polymeric surface coating. For example, a decrease in the surface coating permeability and increase in selectivity and solute rejection could result from lower cross linking density when a semi-crystalline polymer is employed. A decrease in crosslinking density can increase the crystalline structure of the polymer, resulting in a tighter polymer chain packing or aggregate structure with increased hydrophilicity $[47,48]$. Interestingly, another study [46] suggests that high selectivity and solute rejection of the polymeric surface coating should increase with crosslinking density-lower membrane hydrophilicity was reported at higher crosslinking densities. Based on the significant decrease in the RSF and solute permeability of TFC2 and its significant increase in hydrophilicity after exposure to produced water (Table $5)$, we speculate that this membrane is coated with a semi-crystalline polymer whose crosslinking density decreased due to specific interaction with dissolved compounds in the feed water $[47,48]$. It should be noted that an increase in the TFC2 crosslinking density in the polymer film could also explain the increase in solute rejection; however, this is highly unlikely because the increase in surface hydrophilicity resulting from exposure to produced water must overcome any increase in the internal polymer hydrophobicity due to induced crosslinking of the hydrogel coating.

The observed changes in membrane performance and permeability coefficients, even after thorough CEOB, translate into a lower average SRSF after exposure to produced water $(2.2 \pm 0.4 \mathrm{mM} / \mathrm{L})$ compared to the virgin membrane coupon $(4.0 \pm 0.4 \mathrm{mM} / \mathrm{L})$. Interestingly, and unlike the TFC1 membrane, the significant decline in SRSF and solute permeability validate the changes in TFC2 membrane performance observed in our previous study (Figure 1a and 1b). Phenomena like ICP cannot explain the observed change in TFC2 performance alone. This is especially true considering that RSF declined concurrently with water flux regardless of the lower structural parameter modeled for the membrane. Cake enhanced 
concentration polarization is also very unlikely given the similar water flux before and after exposure to produced water and the lack of visible fouling on the membrane surface after CEOB. Regardless, these results provide exciting insights into the successful coating of a polyamide TFC membrane for FO, whose water permeability exceeds that of CTA while exhibiting superior solute rejection and significantly reduced RSF.
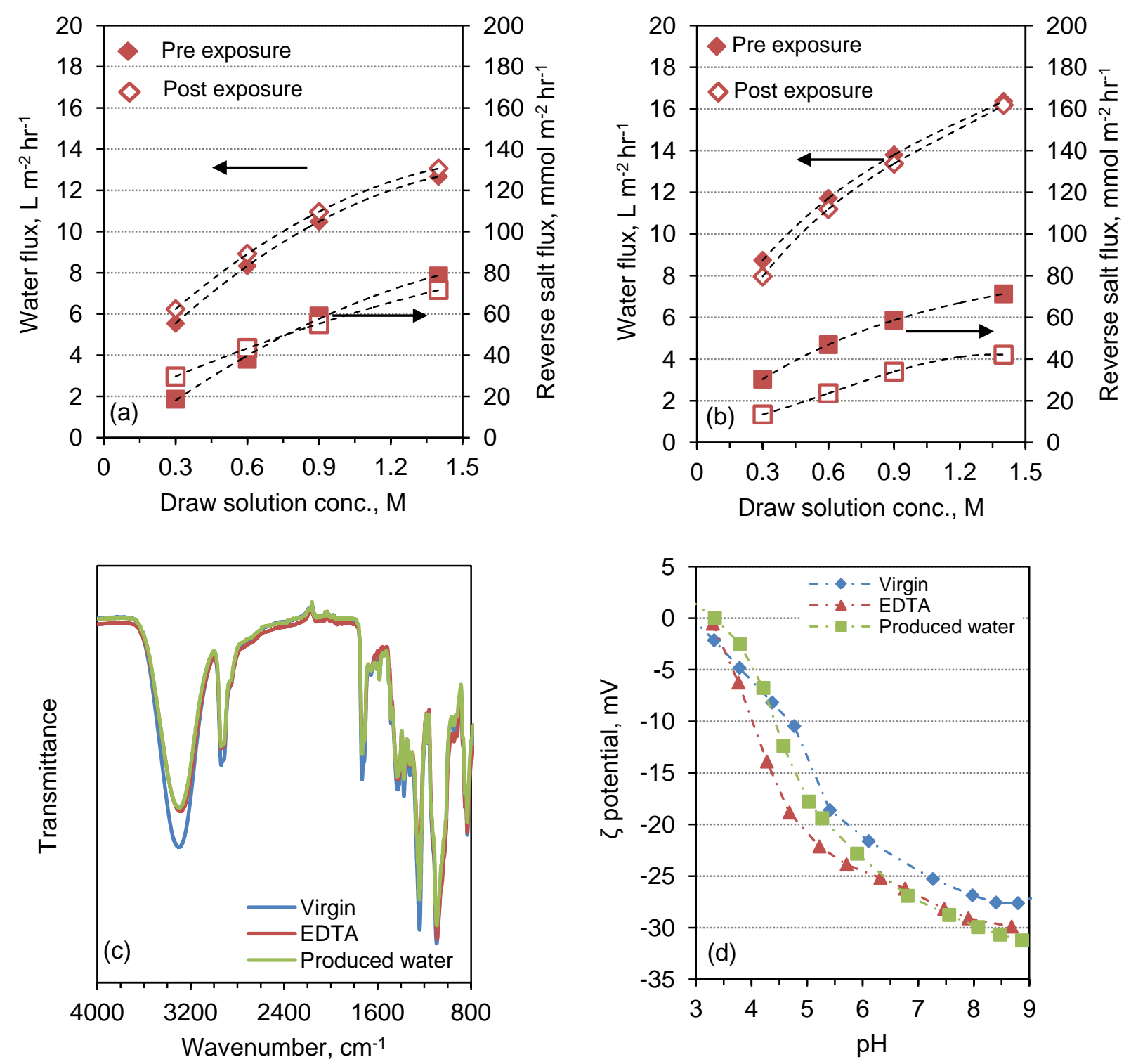

Figure 4. Membrane deionized feed water performance is compared for (a) virgin TFC2 membrane before and after exposure to EDTA for 2 hrs and for (b) virgin TFC2 membrane before and after exposure to produced water and CEOB with EDTA. (c) FTIR spectra and (d) zeta potential of TFC2 membrane coupons are also compared to identify if any differences in the chemical and electrokinetic properties of each membrane following exposure to cleaning and feed solutions. 
Table 5. TFC2 membrane physiochemical surface properties

\begin{tabular}{|c|c|c|c|}
\hline \multirow{2}{*}{ Surface property } & \multicolumn{3}{|c|}{ TFC1 } \\
\hline & Virgin & EDTA $^{c}$ & $\mathrm{PW}^{\mathrm{d}}$ \\
\hline$A\left(L^{-2} \mathrm{hr}^{-1} \mathrm{bar}^{-1}\right)$ & 1.16 & - & 0.748 \\
\hline $\mathrm{B}\left(\mathrm{L} \mathrm{m}^{-2} \mathrm{hr}^{-1}\right)$ & 0.234 & - & 0.089 \\
\hline$S(\mu \mathrm{m})$ & 489 & - & 354 \\
\hline$C V^{a}$ & 10.46 & - & 9.54 \\
\hline$R^{2}-J_{W}$ & 0.975 & - & 0.980 \\
\hline$R^{2}-J_{S}$ & 0.987 & - & 0.983 \\
\hline Contact angle $^{\mathrm{b}},\left(^{\circ}\right)$ & $35.9 \pm 5.0$ & $34.2 \pm 2.4$ & $20.5 \pm 4.6$ \\
\hline$\Delta \mathrm{G}_{\mathrm{sws}}\left(\mathrm{mJ} / \mathrm{m}^{2}\right)$ & 5.8 & 17.5 & 34.2 \\
\hline$\gamma^{\llcorner\mathrm{W}}\left(\mathrm{mJ} / \mathrm{m}^{2}\right)$ & 38.8 & 39.7 & 37.4 \\
\hline$\gamma^{+}\left(\mathrm{mJ} / \mathrm{m}^{2}\right)$ & 2.2 & 0.8 & 0.8 \\
\hline$\gamma^{-}\left(\mathrm{mJ} / \mathrm{m}^{2}\right)$ & 33.6 & 41.3 & 54.4 \\
\hline
\end{tabular}

${ }^{a} \mathrm{CV}$ is the coefficient of variation of $\mathrm{J}_{\mathrm{w}} / \mathrm{J}_{\mathrm{s}}$. CV is defined as the standard deviation divided by the arithmetic mean

${ }^{\mathrm{b}}$ Deionized water using captive bubble method

${ }^{\mathrm{c}} \mathrm{FO}$ modeling was conducted on membrane coupons exposed to produced water

${ }^{\mathrm{d}}$ Produced water

\subsection{Contaminant rejection: Validation of membrane performance}

The rejection of dominant feed stream contaminants was measured during exposure to produced water and before CEOB. The goal was to identify unique trends in contaminant rejection to corroborate changes in membrane performance and solute permeability observed during subsequent deionized feed water testing. Specifically, the rejection of feed stream constituents by the TFC2 membrane was of interest given its unique surface coating and the significant decrease in its solute permeability observed here and in our previous study [9]. Due to the complex nature of produced water and its high concentration of sodium and chloride, RSF was not calculated concurrently with contaminant rejection. The concentrations of major feed stream anions in the DS were also below the detection limits of the ion chromatograph throughout the study.

The percent rejection of feed stream cations, DOC, and TN for the three membranes is compared in Figure 5. Lower contaminant rejection by TFC1 was expected given its high $\mathrm{B}$ coefficient relative to the CTA and TFC2. The significant decrease in its modeled structural parameter also likely decreased the effects of dilutive ICP, thereby increasing RSF into the feed and exacerbating bi-directional solute flux to maintain solution electroneutrality $[49,50]$. Contaminant rejection by the CTA membrane was higher than that of TFC1, which is in agreement with its significantly lower solute permeability. However, despite having the lowest solute permeability (virgin membrane) in this study and in our previous investigation [9], the rejection of produced water contaminants by the CTA membrane was lower than that of TFC2 across almost all major feed analytes. These rejection data have proven repeatable [9] and corroborate the modeled decrease in TFC2 solute permeability. 


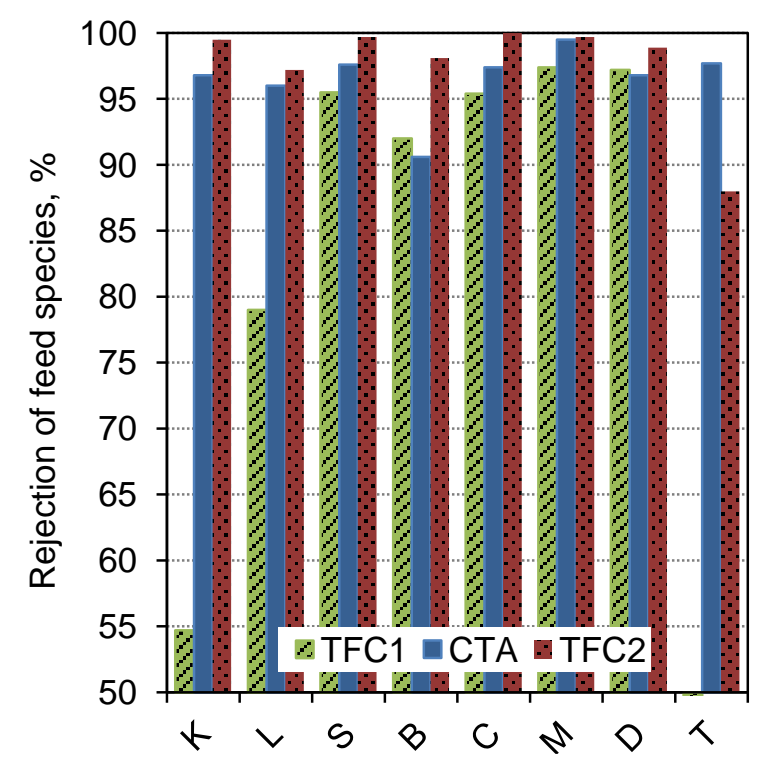

Figure 5. Rejection of dissolved ions, dissolved organic carbon, and total nitrogen by the CTA, TFC1, and TFC2 membranes. *Total nitrogen rejection for TFC1 was 35\%.

To further validate the superior rejection of the TFC2 membrane, the preferential transport and overall rejection of dissolved organic compounds by the three FO membranes were investigated by conducting a non-targeted screening of all DS samples during treatment of produced water. Colored bands in each heat map represents the absence (blue) or strong presence (red) of dissolved organic compounds in each sample. Results from LC/Q-TOF and GC/Q-TOF were de-convoluted to show only organic compounds present in the DS samples that were unique to the produced water feed. In other words, compounds that appeared in the DS samples due to leaching from bench-scale system and from trace contaminants in the $\mathrm{NaCl}$ salt are not shown. Heat maps from LC/Q-TOF analyses are organized by increasing molecular weight (Figure 6a), while those from GC/Q-TOF are organized by increasing retention time (Figure 6b). Mass/charge numbers for GC/Q-TOF results at each retention time are also shown $((\mathrm{m} / \mathrm{z}), \mathrm{min})$. Similar to rejection data presented in Figure 5, the TFC2 membrane exhibited superior rejection of dissolved organic compounds present in the produced water feed. The TFC2 behaved as a tighter membrane, as shown by the decrease in organic compound prevalence with increasing molecular weight (Figure 6a). While a direct comparison between compound rejection and molecular weight cannot be inferred with the GC/Q-TOF results, the superior rejection of volatile organic compounds by TFC2 was clearly visible. 

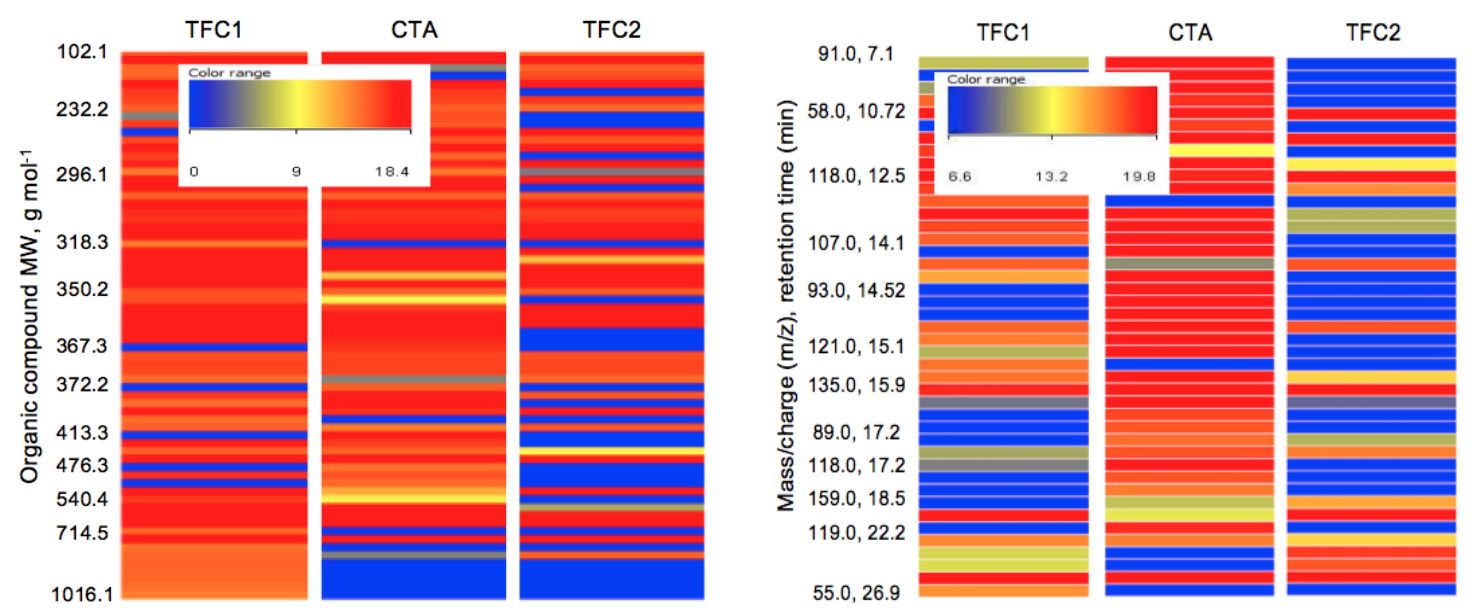

Figure 6. Heat maps for the TFC1, CTA, and TFC2 DS samples taken after $48 \mathrm{hrs}$ of exposure to produced water. Color bands in the (a) LC/Q-TOF and (b) GC/Q-TOF heat maps represent the absence (blue) or strong presence (red) of organic compounds (unique to the produced water feed) that were present in the DS. Of the 1109 organic compounds identified in the feed using LC/Q-TOF, 72 were present in the TFC1 DS, 52 in the CTA DS, and 39 in the TFC2 DS. Of the 603 organic compounds identified in the feed using GC/Q-TOF, 30 were present in the TFC1 DS, 38 in the CTA DS, and 20 in the TFC2 DS.

Note that while the rejection of dissolve organic compounds by CTA using LC/Q-TOF correlated well with membrane solute permeability after exposure to produced water, the rejection of volatile organic compounds as shown by GC/Q-TOF do not. Lower than expected rejection of volatile organic compounds by CTA is likely due to its slightly hydrophobic character (relative to the polyamide membranes), which promoted a higher degree of hydrophobic hydrocarbon sorption to the membrane surface. This would effectively increase the concentration gradient across the CTA active layer and promote enhanced diffusion into the DS. Similar results have been presented in the literature where FO membranes have been investigated for removal of trace organic compounds from various feed waters [51, 52].

\section{Conclusions}

Results from the current study suggest that in the short term, commercially available CTA and TFC membrane are chemically and physically stable during treatment of raw produced waters from O\&G exploration; however, some minor changes in membrane performance might be expected in future industrial applications. CTA and TFC1 showed no apparent changes in their physiochemical properties after CEOB using EDTA, indicating that changes in membrane performance are purely a result of exposure to produced water. Each of the two membranes did experience slight decreases in their transport and structural parameters after produced water treatment, corresponding to an irreversible decrease in permeability due to osmotic de-swelling and charge neutralization. Given the complex nature of the produced water feed stream, sorption and entrapment of dissolved organics and hydrocarbons in the active layer of CTA and TFC1 might also have hindered solute and water transport through these membranes. Interestingly, a significant increase in CTA hydrophilicity was observed resulting from 
changes in the acid-base properties of the membrane surface, while minimal variations in TFC1 hydrophilicity were measured.

In this study, we also report on the performance of an early generation surface coated TFC membrane designed specially for FO applications. The polyamide TFC membrane was coated with a hydrogel to increase the antifouling properties of the membrane active layer. While the virgin membrane exhibited impressive water permeability and solute rejection compared to the uncoated TFC1 membrane, the TFC2 membrane performed even more remarkably after exposure to produced water. The water permeability of TFC2 slightly deceased-similar to CTA and TFC1—but the RSF of the membrane favorably decreased by over $50 \%$. After exposure to produced water and subsequent cleaning the membrane still exhibited higher water permeability than the CTA membrane; yet, its solute permeability coefficient was lower by $32 \%$. While the exact reasoning for changes in the TFC2 surface coating are not yet know, the successful application and impressively low solute transport properties of the surface coated TFC2 membrane mark a new chapter in the rapid progression of FO membranes for treatment of complex feed waters.

\section{Acknowledgements}

Support of this investigation was provided by DOE/RPSEA project $10122-39$ and by the NSF/SRN program under Cooperative Agreement No. CBET 1240584. The authors would like to thank Hydration Technology Innovations for providing membranes for the study. The authors would like to thank Estefani Bustos and Nohemi Almaraz for their assistance with laboratory analyses and membrane characterization and to Tani Cath for his technical support. The CSM Undergraduate Research Fellowship Program is acknowledged for their financial support of Nohemi Almaraz during this investigation.

\section{References}

[1] K.O. Agenson, J.-I. Oh, T. Urase, Retention of a wide variety of organic pollutants by different nanofiltration/reverse osmosis membranes: controlling parameters of process, J. Membr. Sci. 225 (2003) 91-103.

[2] S. Al-Jeshi, A. Neville, An experimental evaluation of reverse osmosis membrane performance in oily water, Desalination 228 (2008) 287-294.

[3] S. Alzahrani, A. Mohammad, N. Hilal, P. Abdullah, O. Jaafar, Comparative study of NF and RO membranes in the treatment of produced water-Part I: Assessing water quality, Desalination 315 (2013) 18-26.

[4] S. Alzahrani, A. Mohammad, N. Hilal, P. Abdullah, O. Jaafar, Comparative study of NF and RO membranes in the treatment of produced water II: Toxicity removal efficiency, Desalination 315 (2013) 27-32.

[5] S. Alzahrani, A.W. Mohammad, P. Abdullah, O. Jaafar, Potential tertiary treatment of produced water using highly hydrophilic nanofiltration and reverse osmosis membranes, J. Environ. Chem. Eng. 1 (2013) 1341-1349. 
[6] R. Franks, C. Oceanside, L. Nagghappan, Performance of a reverse osmosis system when reclaiming high $\mathrm{pH}$-high temperature wastewater, Proceedings of the American Water Works Association Membrane Technology Conference, Memphis, TN, 2009.

[7] T. Hodgkiess, W. Hanbury, G. Law, T. Al-Ghasham, Effect of hydrocarbon contaminants on the performance of RO membranes, Desalination 138 (2001) 283-289.

[8] S. Zhang, P. Wang, X. Fu, T.-S. Chung, Sustainable water recovery from oily wastewater via forward osmosis-membrane distillation (FO-MD), Water Res. 52 (2014) 112-121.

[9] B.D. Coday, N. Almaraz, T.Y. Cath, Forward osmosis desalination of oil and gas wastewater: Impacts of membrane selection and operating conditions on process performance, J. Membr. Sci. 488 (2015) 40-55.

[10] C.H. Webb, L. Nagghappan, G. Smart, J. Hoblitzell, R. Franks, Desalination of oilfield-poduced water at the San Ardo Water Reclamation Facility CA, SPE Western Regional Meeting, San Jose, CA, 2009.

[11] B.D. Coday, P. Xu, E.G. Beaudry, J. Herron, K. Lampi, N.T. Hancock, T.Y. Cath, The sweet spot of forward osmosis: Treatment of produced water, drilling wastewater, and other complex and difficult liquid streams, Desalination 333 (2014) 23-35.

[12] D.L. Shaffer, L.H. Arias Chavez, M. Ben-Sasson, S. Romero-Vargas Castrillón, N.Y. Yip, M. Elimelech, Desalination and reuse of high-salinity shale gas produced water: drivers, technologies, and future directions, Environ. Sci. Technol. 47 (2013) 9569-9583.

[13] K.L. Hickenbottom, N.T. Hancock, N.R. Hutchings, E.W. Appleton, E.G. Beaudry, P. Xu, T.Y. Cath, Forward osmosis treatment of drilling mud and fracturing wastewater from oil and gas operations, Desalination 312 (2013) 60-66.

[14] B.D. Coday, T.Y. Cath, Forward osmosis: novel desalination of produced water and fracturing flowback, J. AWWA 106 (2014) 37-38.

[15] B.D. Coday, L. Miller-Robbie, J. Munakata-Marr, E.G. Beaudry, T.Y. Cath, Life cycle and economic assessments of engineered osmosis and osmotic dilution for desalination of Haynesville shale pit water, Desalination 369 (2015) 188-200.

[16] P. Xu, J.E. Drewes, Viability of nanofiltration and ultra-low pressure reverse osmosis membranes for multi-beneficial use of methane produced water, Sep. Purif. Technol. 52 (2006) 67-76.

[17] A. Fakhru'I-Razi, A. Pendashteh, L.C. Abdullah, D.R.A. Biak, S.S. Madaeni, Z.Z. Abidin, Review of technologies for oil and gas produced water treatment, J. Environ. Chem. Mater. 170 (2009) 530-551.

[18] Aromatics in produced water: occurence, fate \& effects, and treatment, 2002, International Association of Oil and Gas Producers, http://www.ogp.org.uk/pubs/324.pdf

[19] U.S. Department of the Interior - Bureau of Reclamation, Oil and gas produced water management and beneficial use in the western United States, (2011) http://www.usbr.gov/.../report157.pdf

[20] A. Tiraferri, N.Y. Yip, A.P. Straub, S. Romero-Vargas Castrillon, M. Elimelech, A method for the simultaneous determination of transport and structural parameters of forward osmosis membranes, J. Membr. Sci. 444 (2013) 523-538. 
[21] J.M. Neff, T.C. Sauer Jr, Aromatic hydrocarbons in produced water, in: Produced Water 2, Springer, 1996, p 163-175.

[22] M.H. Owadally, Effects of hydrocarbon fouling on reverse osmosis membranes, University of Glasgow, Masters Thesis, (2009).

[23] T. Yun, J.-W. Koo, J. Sohn, S. Lee, Pressure assisted forward osmosis for shale gas wastewater treatment, Desalin. Water Treat. 54 (2014) 829-837.

[24] R.L. McGinnis, N.T. Hancock, M.S. Nowosielski-Slepowron, G.D. McGurgan, Pilot demonstration of the $\mathrm{NH} 3 / \mathrm{CO} 2$ forward osmosis desalination process on high salinity brines, Desalination 312 (2013) 67-74.

[25] X.-M. Li, B. Zhao, Z. Wang, M. Xie, J. Song, L.D. Nghiem, T. He, C. Yang, C. Li, G. Chen, Water reclamation from shale gas drilling flow-back fluid using a novel forward osmosis-vacuum membrane distillation hybrid system, Water Sci. Technol. 69 (2014) 1036-1044.

[26] N.R. Hutchings, E.W. Appleton, R.A. McGinnis, Making high quality frac water out of oilfield waste, Proceedings of the SPE Annual Technical Conference and Exhibition, Florence, Italy, 2010.

[27] B.D. Coday, D.M. Heil, P. Xu, T.Y. Cath, Effects of transmembrane hydraulic pressure on performance of forward osmosis membranes, Environ. Sci. Technol. 47 (2013) 2386-2393.

[28] T.Y. Cath, M. Elimelech, J.R. McCutcheon, R.L. McGinnis, A. Achilli, D. Anastasio, A.R. Brady, A.E. Childress, I.V. Farr, N.T. Hancock, Standard methodology for evaluating membrane performance in osmotically driven membrane processes, Desalination 312 (2013) 31-38.

[29] N. El Shaari, M. Kedzierski, T. Gorham, Quantifying guar polymer recovery post hydraulic fracturing to determine the degree of fracture cleanup: A field study of the point of rocks formation california, Proceedings of the SPE Western Regional Meeting, Irvine, CA, 2005.

[30] R. Barati, J.T. Liang, A review of fracturing fluid systems used for hydraulic fracturing of oil and gas wells, J. Appl. Polym. Sci. 131 (2014) 1-11.

[31] S. Merel, T. Anumol, M. Park, S.A. Snyder, Application of surrogates, indicators, and highresolution mass spectrometry to evaluate the efficacy of UV processes for attenuation of emerging contaminants in water, J. Environ. Chem. Mater. 282 (2015) 75-85.

[32] B.D. Coday, T. Luxbacher, A.E. Childress, N. Almaraz, P. Xu, T.Y. Cath, Indirect determination of zeta potential at High lonic strength: specific application to semipermeable polymeric membranes, J. Membr. Sci. 478 (2015) 58-64.

[33] A.E. Childress, M. Elimelech, Effect of solution chemistry on the surface charge of polymeric reverse osmosis and nanofiltration membranes, J. Membr. Sci. 119 (1996) 253-268.

[34] J.A. Brant, A.E. Childress, Assessing short-range membrane-colloid interactions using surface energetics, J. Membr. Sci. 203 (2002) 257-273.

[35] G. Hurwitz, G.R. Guillen, E. Hoek, Probing polyamide membrane surface charge, zeta potential, wettability, and hydrophilicity with contact angle measurements, J. Membr. Sci. 349 (2010) 349357.

[36] M.C. Wong, K. Martinez, G.Z. Ramon, E.M. Hoek, Impacts of operating conditions and solution chemistry on osmotic membrane structure and performance, Desalination 287 (2012) 340-349. 
[37] G. Mehta, S. Loeb, Performance of permasep B-9 and B-10 membranes in various osmotic regions and at high osmotic pressures, J. Membr. Sci. 4 (1979) 335-349.

[38] H. Massaldi, C. Borzi, Non-ideal phenomena in osmotic flow through selective membranes, J. Membr. Sci. 12 (1982) 87-99.

[39] Y. Mo, Effects of water chemistry on NF/RO membrane structure and performance, University of California Las Angeles Masters Thesis, (2013).

[40] V. Freger, T. Arnot, J. Howell, Separation of concentrated organic/inorganic salt mixtures by nanofiltration, J. Membr. Sci. 178 (2000) 185-193.

[41] A. Simon, W.E. Price, L.D. Nghiem, Impact of chemical cleaning on the nanofiltration of pharmaceutically active compounds (PhACs): The role of cleaning temperature, J. Taiwan Inst. Chem. Eng. 44 (2013) 713-723.

[42] J. Ricka, T. Tanaka, Swelling of ionic gels: quantitative performance of the Donnan theory, Macromolecules 17 (1984) 2916-2921.

[43] I.L. Alsvik, K.R. Zodrow, M. Elimelech, M.-B. Hägg, Polyamide formation on a cellulose triacetate support for osmotic membranes: Effect of linking molecules on membrane performance, Desalination 312 (2013) 2-9.

[44] J.R. McCutcheon, M. Elimelech, Influence of membrane support layer hydrophobicity on water flux in osmotically driven membrane processes, J. Membr. Sci. 318 (2008) 458-466.

[45] J. Ren, J.R. McCutcheon, A new commercial thin film composite membrane for forward osmosis, Desalination 343 (2014) 187-193.

[46] B. Bolto, T. Tran, M. Hoang, Z. Xie, Crosslinked poly (vinyl alcohol) membranes, Prog. Polym. Sci. 34 (2009) 969-981.

[47] F. Peng, X. Huang, A. Jawor, E.M. Hoek, Transport, structural, and interfacial properties of poly (vinyl alcohol)-polysulfone composite nanofiltration membranes, J. Membr. Sci. 353 (2010) 169176.

[48] F. Peng, Z. Jiang, E.M. Hoek, Tuning the molecular structure, separation performance and interfacial properties of poly (vinyl alcohol)-polysulfone interfacial composite membranes, J. Membr. Sci. 368 (2011) 26-33.

[49] N.T. Hancock, T.Y. Cath, Solute coupled diffusion in osmotically driven membrane processes, Environ. Sci. Technol. 43 (2009) 6769-6775.

[50] N.T. Hancock, W.A. Phillip, M. Elimelech, T.Y. Cath, Bidirectional permeation of electrolytes in osmotically driven membrane processes, Environ. Sci. Technol. 45 (2011) 10642-10651.

[51] B.D. Coday, B.G. Yaffe, P. Xu, T.Y. Cath, Rejection of trace organic compounds by forward osmosis membranes: a literature review, Environ. Sci. Technol. 48 (2014) 3612-3624.

[52] N.T. Hancock, P. Xu, D.M. Heil, C. Bellona, T.Y. Cath, Comprehensive bench-and pilot-scale investigation of trace organic compounds rejection by forward osmosis, Environ. Sci. Technol. 45 (2011) 8483-8490. 